\title{
Science and Religion from a Catholic Perspective
}

In this final chapter we place the reconstructed and analysed discourses from francophone Africa in the framework of the wider debate on science and religion. In the first chapter we explained with the help of Bagir (2015), Livingstone (1999, 2003 and 2011), and others how the terms, science and religion, as well as the supposed relationship between the two already point to the Western origin of the debate. Designed in Europe and using a typical Western frame, our research of the understandings from francophone Africa is therefore also biased and mainly informed by typical Western suppositions and reflexes. When we focus in this chapter on relating these discourses from French-speaking Africa to a wider debate, this biased framework easily becomes a hindrance. A normative Western approach in the sciences alienates a person from their own background (Zhou 2012) and therefore diminishes the possibilities of a worldwide and open dialogue. This of course prevents a real exchange of ideas and knowledge. However, the discourses from French-speaking Africa show that the participants mainly understand science tout court as Western science (see Chapter 4). ${ }^{1}$ Western normativity is therefore not only present on the side of Western researchers, but is also part of the discourses from French-speaking Africa as well. Therefore, we do not pretend we can avoid this bias, but we try to diagnose it more carefully in order to understand its function and limitations.

The search for a better and more critical understanding of the normative function of Western perspective on science is part of a broader venture. We join Willem Drees (2015) when he qualifies the task of a global approach to science and religion as both descriptive and hermeneutical. Chapters 4 and 5 offer a description of some discourses on science from French-speaking Africa and also include the first steps of the hermeneutics by analysing and comparing the discourses. In Chapters 6 and 7 we continue this process, putting the reconstructed views on science and faith into a wider perspective in order to discover their possible contribution to a more intercultural and global approach. Chapter 6 offers our perspective on the connection between the studied discourses and (the development of) intercultural theology. In this chapter we concentrate on the relation to the wider debate on science and religion. In the first section we offer a sketch of the two tendencies we find in the

1 See Chapter 4. 
bibliography when a global approach to the understandings of science and religion is in view. Historians seem to be especially focussed on the tremendous local and historical diversity and complexities of the positions while most (systematic) theologians concentrate on the universal aspects of science and faith. In line with Chapter 6 we will develop an alternative, catholic approach that tries to include some important points from both perspectives. The limitations of the scope of our research on Christian faith does not imply that our understanding of the catholic approach is only valuable for Christian faith.

Indeed, other religious or philosophical worldviews are also invited to contribute. From our understanding the many possible ways to understand "the interaction between knowledge and values," as Drees (2015) puts it, become even more interesting and worthwhile when a proper contribution from one cultural approach to another can be worded. Although we recognize with Efron that "[f] ocussing on the historically specific, the contingent, the unique, the sui generis, makes it difficult to bring any given moment in time and space to bear on any other moment" $(2010,252)$, we do think this is possible.

In the second section, we consider some important characteristics of the encounter between the debates from different cultural backgrounds. Finally, we specify these considerations, identifying contributions from the studied discourses to the Western debate on science and religion and vice versa, and answering the question of how these interchanges enable the development of our knowledge of God.

\section{$\mathbf{1}$ \\ Towards a Global Approach to Science and Religion}

According to William Drees, a global approach to the questions related to science and religion is a desideratum in times of globalization. His efforts as editor of Zygon to come to a more global overview of the state of the art in different world regions is provocative and highly interesting, but it does not necessarily lead to a better understanding of the interrelation of specific (local or regional) situations. In the series of articles called "(the future of) religion and science around the world" published in 2015 there is explicit attention paid to the world outside the North Atlantic. For example, Ignacio Silva's portrayal of Latin America is an informative overview of the persons and activities that animate the debate in different Latin American countries, but does not offer an overview or an in depth understanding of the complexities of the Latin American versions of the debate on religion and science. Although we agree that this and other articles point to the great potential of a global approach, we conclude that in the current situation a global approach to science and 
religion is still more desired than practised. We only have bits and pieces without a framework that permits comparison and without an overview of the diversity of understanding. This is not meant to discourage the focus on a more global approach, but to raise awareness about the different understandings of what a global approach is or should be. In the first section of this chapter we distinguish three approaches to the global perspective. The first one is focussed on the complexity of the global situation, the second one underlines the universality of the science and religion debate. At the end of the section we will add our alternative approach that is based on the notion of catholicity.

\subsection{Complexity Approaches}

The study of the history of science and religion has strongly pushed the debate in the direction of a global approach. In the foregoing chapters we already referred to authors such as Brooke, Numbers, and Livingstone who repeatedly point to the historical complexity of what is called science and religion. For example, Livingstone's geographic approach in Putting Science in Its Place (2003) is very helpful for understanding the direct relationship between science, including both its practices and its theories, and its cultural (including social and political) context. The case of the diverse responses to Darwin's theories by different Reformed communities in the Anglophone world is regularly referred to, and makes it tangible that even a well-defined shared theological framework does not exclude very different scholarly evaluations (Livingstone 2003, 116-121). According to Livingstone, local situations therefore play a decisive role in science. Science is not a "perspective from no-where" $(2003,184)$. Noah Efron, who enthusiastically portrays the contributions of John Hedley Brooke in this field, mentions Brooke's effort in Science and Religion: Some Historical Perspectives (1991) to de-reify both science and religion (2010, 248-249). Efron argues that after the publication of the book, despite the acclaim it received, the search for "something timeless in the nature of the relationship between 'science' and 'religion'" continued, for example in the understanding of different religious traditions towards science, like 'the Muslim view' or 'the Jewish view' $(2010,252)$. Nevertheless, he thinks that the real complexity is avoided.

This focus on complexity does not mean that all these authors deny the possibility of a more general or transcending perspective. Although very dedicated to the complexity approach, Ronald Numbers opens another window when he turns towards what he calls 'patterns' in the history of science and religion:

Without abandoning the gospel of complexity and retreating to uncomplicated master-narratives we can - and I believe should - search for 
middle-scale patterns, whether epistemic or social, demographic or geographical, theological or scientific.... I shall therefore contribute to this task by offering five such middle-scale generalizations, addressing what I call naturalization, privatization, secularization, globalization and radicalization.

NUMBERS 2010, 264

However, these five generalizations reveal some interesting presuppositions in Numbers' perspective. The first three generalizations are closely connected to the separation of 'science' and 'religion' which has dominated the debate in most of the North Atlantic world since the nineteenth century (Harrison 2010; Bagir 2015). Although naturalization, privatization and secularization might have a strong impact on the development of perspectives in the North Atlantic world, this cannot be assumed for the rest of the globe. The dominant perception in the discourses we studied from francophone Africa is a unified understanding of science and faith. According to $\operatorname{Bagir}(2015,415)$ this is also the case in the traditional understandings from Indonesia, and this also appears to be the case in India (Raghuramaraju 2016). Numbers' understanding of middlescale patterns therefore reflects a biased Western understanding and is not helpful for discovering 'middle-scale generalizations' that include cultural diversity worldwide.

Globalization and radicalization, the last two middle-scale generalizations mentioned by Numbers, do not necessarily depend on this separation, and are more promising. However, these more sociologically coined patterns are less helpful for finding shared content than they might seem. For example, the dissemination of creationism in Turkey, as is testified to by Harun Yahya's Atlas of Creation (Hameed 2010, 133 and 149), can easily be recognized as being co-produced by globalization. However, globalization does not explain the meaning of 'creationism' in this specific cultural context (Drees 2010, 150). In other words, the global inspiration (in this case mainly from a North American background) is received and elaborated locally and therefore produces distinct effects and meanings (Roggeband 2007).

\subsection{Universalist Approaches}

The attention paid to the global diversity of the understanding of science and religion among theologians is less usual and more recent. The relatively late recognition of its importance, by Drees (2010), for example, is meaningful. At least two developments should have earlier opened eyes to the importance of global diversity for theological reflection on this point. Firstly, take the approval of Kuhn's historical approach to science (cf. Brink, 2009, $46 \mathrm{ff}$. and 193ff.). 
Although Kuhn's theory about the major paradigm shifts in the past was widely recognized, theologians apparently did not relate the historical diversity of scientific paradigms to the cultural diversity. Drees (2010, 59-60) reveals at least one reason why theologians sometimes refrain from the use of Kuhn's theory. According to him, Kuhn's argument could be abused in a 'tu quoque argument' suggesting that a loss of credibility for science would be a gain for theology. "Downplaying science," as Drees argues, is often based on a simplification of scientific approaches. Feierman \& Janzen (2011) point to another way systematic theology from the West could have been informed about alternative understandings of science and religion. Western missionaries communicated extensive information about scientific engagement in other cultures, but this knowledge was not used to inform the position of (Western) systematic theologians in the science and religion debate. The restraint among systematic theologians in making use of the historical and local diversity in their argumentation is also related to the specialisation from which science and religion is studied. Most theologians involved in the debate tend to be connected to analytical philosophy, which is focussed on the logical structures of thought and not so much on its historical and cultural situation. This is the case for Van Huyssteen and Van den Brink for example. Among these theologians, some are natural scientists themselves, as in the case of Barbour, Polkinghorne, and Drees.

To understand this attitude better, we turn to an example of a concrete and influential theological contribution to the science and religion debate. We choose Wentzel van Huyssteen's Alone in the World? Human Uniqueness in Science and Theology (2006), a major theological publication in the field of science and religion in the last twenty years. This book was published some years after a number of influential publications by complexity thinkers such as Livingstone's ground-breaking Putting Science in Its Place.

In the debate on Van Huyssteen's book, theologian Nancy Howell argues that Van Huyssteen does not sufficiently take account of the Western cultural bias of his focus on the uniqueness of human being (Zygon 2008). In reference to the difference between Japanese and Western scientists observed by the famous primatologist Frans de Waal, Howell argues that, contrary to Western colleagues, human uniqueness was not really an issue for the Japanese primatologists because of "the absence of human-animal dualism in the culture and religions that shaped Japanese worldviews" (Howell 2008, 494). Howell's critical assessment of Van Huyssteen's position is based on the lack of care used in the application of Van Huyssteen's own contextual and experience based postfoundationalist epistemology. “By Van Huyssteen's postfoundationalist approach to theology and science we should expect culturally determined 
differences to arise in diverse contexts" (495). This "cultural determination" affects (Western) paleoanthropology, Howell argues: "Scientific claims appear to be reminiscent of Christian historical theology in its quest to define the image of God (imago Dei) and human uniqueness in contrast to animals" (496). Howell's argument is therefore that Van Huyssteen's approach does not take sufficient critical distance from his project in order to understand its "situated particularity." According to Howell, "Social location" and "cross-cultural and religious comparative reflection" should have informed Van Huyssteen's approach (497). Although cross-cultural diversity appears to be at the heart of Van Huyssteen's rationality (Van Huyssteen 2006, 12-13, 24-25, 33), he nevertheless fails to adequately address the social location of Western science - in this case its understanding of humanity.

In his response, Van Huyssteen admits the validity of Howell's critical remarks but he does not analyse why he did not raise the issue of the different cultural perspectives on humanity, as is testified to by the example of the Japanese primatologists $(2008,523)$. This is particularly interesting because Van Huyssteen is a white South-African theologian, and at least the geographical position of his primary social location creates a clear distance from the North Atlantic. Yet, even if Van Huyssteen were to identify himself theologically as completely or mainly connected with the Western world, the influence of this social and cultural location is equally relevant. However, the nicely elaborated conclusions of the book Alone in the World? neither testify of the relevance of African cultural involvement nor refer to the influence of the North Atlantic cultural context in relation to the understandings that are presented.

Although Howell's argument is directed towards Van Huyssteen's reception of Western science, in this case, palaeoanthropology, it also concerns Van Huyssteen's theological approach. When Western science as such is not adequately socially situated, this must include the theological positing of the author himself. However, Van Huyssteen's approach in Alone in the World? is far from the traditional universalist approach you might expect. He pays specific attention to the importance of cross-cultural research and severely criticizes modern scientific universalism (Van Huyssteen 2006, 1off.). He even affirms that "it is no longer possible to see theological reflection as an activity in which we can still follow universal rules for understanding" (308). Nevertheless, there is no substantial place given to a reflection on the social and cultural location

2 At this point Howell refers to feminist philosopher Sandra Harding, who requires "strong reflexivity" in order to "achieve critical distance from his/her project in order to engage the socially situated particularity of the project in relation to other cultural projects and the lives of Others" (Howell 2008, 497). For more on Harding, see below. 
of this theological contribution. This lack is due to Van Huyssteen's postfoundationalist approach. Although he recognizes culture and tradition as important influences, his intention is not so much to value these traditional and cultural differences as scientifically fruitful, but as challenges to be overcome. ${ }^{3}$

But a specific tradition is unavoidable only as a starting point, not as a final destination, i.e., not as something that determines or defines later performances.... A post foundationalist approach helps us to realize, however, that we are not the intellectual prisoner of our contexts or traditions, but that we are epistemically empowered to cross contextual, cultural and disciplinary borders to explore critically the theories, meanings and beliefs through which we and others construct our worlds.

VAN HUYSSTEEN 2006, 25

In such an understanding, situation and locality point to the partiality of an approach that has to be repaired. Despite the recognition of the cultural embeddedness of science, there is a crucial difference between Van Huyssteen's approach and that of the historians mentioned above, because cultural diversity is not appreciated as having potential for science, but primarily as something to overcome. In contrast to the historians we mentioned above, the author is focussed on a scientific discourse that transcends cultural contexts and diversities. However, Van Huyssteen not only neglects to take into account the cultural location of the scientific work to which he refers (as Howell points out), but also fails to address the cultural bias of his own research and that of the more general or overarching discourse on which he is focussed. Despite his important criticism of scientific universalism, Van Huyssteen's approach is still universalist when it comes to the appreciation of cultural diversity.

\subsection{A Catholic Approach}

In both arguments we recognize important elements that affirm our intercultural framework. In the first place we want to underline the crucial importance of the contextual and the situational. However, we also want to affirm a certain 'universal' focus, not in the sense of an 'ultimate' understanding of science and religion that eliminates the importance of culturally diverse perspectives, but

3 As Van Huyssteen $(2008,523)$ responds to Howell: "Already in my The Shaping of Rationality I argued that cross-disciplinary, cross-cultural and by implication also comparative religious reflection will expose biases, values, uncritical assumptions and back-ground beliefs and this should indeed - as Howell also argues - raise fundamental questions about our various approaches to the concept of human uniqueness." 
in the sense that both scientific knowledge and knowledge of faith have a relation to a reality which implies that there is a universal point of reference (see the explanation of our 'realistic approach' in Chapter 2). Is there a creative synergy possible between the complexity approach as put forward by historians such as Livingstone, and the emphasis on universalism of the theological approaches such as found in Van Huyssteen's work (despite his own denial)? We think so and for our argument we focus on the theological contributions to the debate. This section starts with the neologism 'glocalisation', which underlines the necessity of an alternative approach, and then takes a historical detour to explain some crucial elements of the understanding of science and Christian faith in early modern Europe. This brings us to the presentation of two fundamental concepts of the catholic approach we propose, trust and community. We end this presentation of our approach with the exploration of the relation between catholic and universal.

\subsubsection{Some Remarks on 'glocalisation'}

Willem Drees makes mention of the question about the universal and the specific focus. In his book entitled Religion and Science in Context: A Guide to the Debates (2010) he uses the term glocal(isation), as we did in Chapter 6, to indicate how local and universal can be related:

Though in their self-understanding and ambitions science and religion are universal, they are set in a particular disciplinary and confessional frame, at a particular place and time. But neither are science and religion just local, as local processes appropriate and adapt discussions going elsewhere.... This interaction between the specific and the general might provide a good framework for considering debates on religion and science. DREES 2010, 148

However, the term glocalisation and its explanation by Drees is very general. It raises important questions such as how the two levels or tendencies relate to each other (for example, is one of the two dominant?) and how they interact. Drees states that "in their self-understanding and ambition, science and religion are universal." However, this is less evident than the author presupposes. His stance reflects a Western understanding of both terms that might be supported by perspectives from other cultures that are driven by universal claims but not by most traditional African religions. Those religions do not make universal claims but are explicitly limited to a people and linked with an ethnic identity. This is therefore also true of traditional African science and is made explicit in the emphasis on secrecy and a lack 
of transparency that are mentioned by the students from Abidjan (see the analysis of the discourse of the students from Abidjan in Chapter 4, cf. Feierman \& Janzen 2011, 245).

Additionally, our research reveals that assuming universality as an essential feature of science also creates problematic situations when we try to gain a global and culturally diverse understanding of science and religion. In these African contexts, the theoretical claims of universality are directly related to Western power and unequal power relations between Northern and Southern hemisphere. When science is mainly understood as 'Western science', the accompanying claims of universality that come along are consequently connected to Western supremacy. This brings into question the value of a specific and thus not universal (or dominating) African perspectives, and this is supported by the last research session with the students from Yaoundé and with the academics from Abidjan. The participants indicated that their research is easily outclassed by Western research because there is so much more funding in Europe and the US (students from Yaoundé) and that African research is often neglected or side-lined (academics from Abidjan). A postcolonial perspective helps to understand why a 'universalist' position is not restricted to (mere) theory and epistemology.

Although we do not deny the importance of what is called 'universal' by Drees, the understanding of this term cannot simply be identified with the Western understanding. This term should therefore be handled very carefully in order to avoid stating that only one specific form of science, in this case Western science, is universal, and that an African or Indonesian form of science is not. Here we join an older epistemological debate, and more specifically Sandra Harding's $(1993,1998)$ understanding of what she called "standpoint epistemology." In this understanding, not only the embodied and situated character of knowledge, but also the crucial importance of communities (instead of primarily individuals) as well as the "genuine dialogue across differences" is advocated (1993, 63-69). We will elaborate this below.

\subsubsection{A Historical Detour}

First we turn to the catholic approach we came up with in Chapter 6. We argued that catholicity offers a wider and deeper understanding of universality; one in which cultural diversity is included. An understanding of the historical developments helps us reflect on the geographically and culturally diverse understandings of science and religion today. The universality claims of modern science from the North Atlantic world are related to the work of 'scientists' from early modernity that was nearly all embedded in a Christian understanding of God and the world (Harrison 2010; Brooke 2011). We referred earlier 
to Peter Harrison who explains that both concepts, 'science' and 'religion', are "of relatively recent coinage" (2015) and that 'science' in particular only took on its modern meaning in the nineteenth century. Harrison concludes that before modern times, in the North Atlantic world 'science' and 'religion' were not independent entities which might bear some positive or negative relation to each other." He refers, among others, to Kepler who described astronomers as "priests of the most high God, with respect to the book of nature" (Harrison 2010, 26).

The early modern case of the condemnation of the theory of Galileo Galilei by the authorities of the Roman Catholic Church is revealing on this point. This intervention reflects the way the authorities understood the 'relationship' between Christian faith and science; in this case as completely intertwined and under their hierarchical authority. However, other Roman-catholic 'natural scientists' involved in the early modern 'sciences' did not agree with the Roman Catholic Church's position. The pointed comment on Rome's verdict on Galileo by the French physician and dedicated Roman Catholic, Blaise Pascal (1623-1662) makes it clear that a faith-related and thus non-independent science does not necessarily lead to suppressive relations between faith and science. He argues that Rome's judgement of Galileo discredits the senses and will have devastating consequences for faith. The reliability of the senses is not only a prime interest for experimental science, but also for the church due to the role of the senses in faith; after all, 'faith is from hearing' (Pascal 1963, 466). According to Pascal, epistemological and anthropological perspectives based on Christian faith should guarantee science's proper functioning. However, Pascal, and others who thought that Galileo's new scientific paradigm was compatible with Christian faith, in no way sought to separate 'science' from 'religion'. Indeed, the reactions of both Rome's authorities and of Pascal, show that in a context where science and religion are intertwined, the claims of science have to be endorsed by theological or religious authorities. The reach of the 'scientific' claims (universal or not) are therefore directly related to the reach of the 'religious' claims (Bom 2012, 352-359). ${ }^{4}$

\subsubsection{Trust and Community as a Basic Layer}

This historical example underlines the crucial roles of faith and trust in both religion and science, as we ourselves underlined at the end of Chapter 6. Pascal

4 Although Pascal recognizes the universal value of faith and certain rational knowledge, he denies the possibility of making universal claims based on scientific experiments, as is testified by his ideas on falsification. He would defend the application of his falsification method as universal as it leads to what he called "certain knowledge," he denies that sensorial knowledge can make universal claims (Bom 1999, 27-29). 
was certainly not the only one in the seventeenth century who based his involvement in experimental, natural science on Christian beliefs (Brooke 2011, 93-94). The basic trust thus relates to a shared faith or worldview. As the case of Pascal makes clear, the reach of the scientific claims is directly related to Christian worldview and thus to God. The Enlightenment and the French revolution primarily relate the basic trust to a universally shared humanity. When, during the nineteenth century, 'science' is separated from 'religion', the foundational role of faith or trust as related to a broader understanding of the world is rejected by positivists (and rationalists) but continues to play an important role in the work of most outstanding scientists, like Darwin, Einstein, etc. (Brooke 2011; Jaeger 1999, 107-121). This trust is not an exclusive individual decision but relates directly to a community and even a culture. In Chapter 6 we recalled not only the importance of the catholic community of faith, but also mentioned science as fundamentally related to a community. This implies an ethical dimension; science is for the good of this community and all people.

With our catholic approach, instead of focussing on complexity or universality, we give priority to the trust or faith and the communal perspective that makes science and Christian faith possible, including its direction towards the good for all. This trust includes the natural and cultural diversity of the reality we know. In this way, global and local come together in a more meaningful, relational, and ethical concept than in the broadly accepted neologism 'glocal'. Catholicity takes the global and the local from the side of the community in which basic trust is fundamental. These two elements relate science and religion more closely than we are used to in the current Western debates.

\subsubsection{Catholic and Universal}

A catholic approach not only reveals some reductive characteristics of an understanding that separates science and religion, but also critiques an ethnically bound understanding of community that is quite common in Africa. The difficulties the student group from Yaoundé had in arguing that a proper African approach could make a contribution to a global debate on science and religion are telling. Starting from their own ethnic sciences they discovered it was impossible to come to a global perspective. Their strongly communitybased understandings are exclusive and are not orientated towards a catholic understanding that includes a plurality of ethnic and cultural identities. Therefore, they mainly related the universal claims of Western sciences to the unequal balance of power and economics, as we explained above. However, a just and fair understanding of the universality of modern science needs a catholic background.

In such an understanding of catholicity the focus on reality, as we elaborated in Chapter 2, cannot be left out (cf. Polanyi's perspective according to Jaeger 
1999, 44-58). In the catholic approach we put forward, this focus on reality undergirds that which is often called universality in the knowledge of both faith and sciences. However, this is not by the exclusion of cultural diversity. Catholicity only functions when various cultural perspectives are included; therefore, an exclusive Western position, despite its many diversities, cannot claim catholicity. In this framework, universality is not one of the points of departure but is rather an aim that is pursued from a catholic, communal approach which starts from trust and takes the ongoing dialogue as its major instrument. There is an interesting parallel here between the way catholic truth was and is formulated by ecumenical synods in which local and regional churches are represented, and the way our catholic approach can move forwards. This reminds us that the (political, economic, etc.) power of the communities involved plays a substantial role in this search that has to be analysed and discussed.

We therefore presuppose that science is multi-cultural in the sense that Christian faith and other religions are multi-cultural. It can be practised within different cultural contexts which will influence its performance and characteristics. In this context, Sandra Harding uses the expression "Cultures as toolboxes for science and technologies," referring more specifically to natural sciences. Harding argues that after World War II, post-colonial, feminist, and post-Kuhnian theories open the floor to a cultural approach to the sciences (Harding 1998, 68-69). Harding rejects neutrality as a condition for what we above called universality. Instead, she focusses on what she calls 'strong objectivity' (see the comment by Nancy Howell above) that helps to "figure out which of these cultural elements are at this particular historical moment advancing and which blocking the growth of knowledge" (Harding 1998, 145).

Harding's perspective is very helpful for the further development of our catholic approach. We want to include different cultural understandings in order to understand the relations between the diverse positions and how together they help to achieve a better understanding of God and creation. We do not intend to present a culturally and religiously 'neutralized' understanding, because catholic never was meant to be neutral. It is about a community based, and God and reality orientated, perspective that intends to include cultural diversity. Therefore, from the very start our catholic approach creates tensions with one-culture approaches, Western or African, but also approaches with the (absolute) separation of faith and science (because of the common ground in faith or trust), and with approaches that separate truth from reality. However, in the debate with these other approaches we see possibilities to grow in the understanding of what is truly catholic. Although in this study we concentrate on Christian faith, our approach explicitly includes the participation of communities from other faiths or worldviews. However, depending on 
the character of those other religions or worldviews, the shared trust will also differ, which will influence the possible outcomes. Nonetheless, we think that differences in beliefs also contribute to the growth of knowledge and strengthen the community-based aspect of our approach. Sometimes, however, there is a wider agreement across cultures that a certain approach is not making any constructive contribution at all.

\subsection{The Focus of a Global Debate on Science and Religion}

Our catholic approach seeks an understanding of both science and religion from a worldwide community in which (cultural) diversity is not seen as a hindrance, but rather as a way to contribute cross-culturally and worldwide. As we have remarked above, from the complexity approach there seems to be no need to think in contributions while every local and cultural determined position can stand on its own. However, Numbers' mid-scale patterns show that at least some complexity scholars cannot resist further generalization. Shared characteristics help to better understand the local diversities in terms of contextualisation and what we have called 'interculturation', and to facilitate thinking in contributions across cultures. Meanwhile, the universality approach tends to see cultural embeddedness as a hindrance to reaching its goal. This approach therefore facilitates the neglect of one's cultural embeddedness which easily results in the universalisation of one's cultural position.

\subsection{Mutual Contributions Across Cultures?}

Above, we pointed to Willem Drees' interest in the diversity of the global perspective on science and religion. In this context, he promotes a functional understanding of the discourse on science and religion. Interestingly, one of the fathers of the complexity approach, John Hedley Brooke, also suggests focusing on functionality (Efron 2010, 250; Brooke, 2014). Drees distinguishes three major roles of this discourse: the apologetic towards outsiders, the provision of authority towards insiders, and finally the resolving of discomfort on a more individual level. Drees argues that these three roles have distinct forms and pursue different purposes at a local level (Drees 2010, 11-38 and 149-150). He argues that this offers more insight into how the diverse and complex understandings of science and religion relate at local and global levels. A nice example of such an apologetic function of the discourse at a local level can be found in the discourse of the students from Abidjan (see Chapter 5 ) which shows that a certain independence of science can be a desideratum in this context.

However, the emphasis on the apologetic function as argued by Drees makes far more sense in a context in which there is a certain common sense about the separation of science and religion. In that case, one of the two or a specific 
relationship between the two has to be defended in a more or less hostile environment. When science and religion are mainly perceived as integrated parts, an understanding that is supported in all groups but is most explicitly expressed by the students from Yaoundé, there is no real internal diversity on this point and the apologetics will therefore be directed against an understanding that separates the two - in this case the Western option. Additionally, the apologetics from the North Atlantic, that presuppose a more or less independent position for both science and religion, are understood as a proclamation of (Western) cultural superiority which inspires cultural politics. This is a common practice in these African countries (see Chapter 3) and not so much as a defence of science and religion in its universal sense as meant by Drees. In this context, giving priority to the apologetic function of the discourse will therefore easily strengthen cultural oppositions. However, instead of strengthening cultural oppositions our intercultural theological approach seeks a dialogue between different cultural perspectives. Although the apologetic function is useful in a context in which a North Atlantic perspective is generally accepted, it does not fit the scope of our intercultural approach.

We therefore reach out to the second function mentioned by Drees: the strengthening of the insiders. From our catholic approach, we understand science and religion as an important theme in worldwide communication which helps local communities from different cultures to respond to the concrete challenges of today's world. In Chapter 6 we already underlined the importance of the words of Paul in Ephesians 3: 18: "with all the Lords holy people" we are able "to grasp how wide and long and high and deep is the love of Christ" (NIV). For this reason, we understand knowledge based on faith to include the knowledge of "all the Lord's people." This implies that the theological knowledge from different cultures is primarily perceived as compatible and complementary, as we elaborated on in Chapter 6.

Concentrating on the strengthening function of the discourse on science and faith for those within the community of faith, we perceive the process of moving towards a global debate as the ongoing understanding of the compatibility and complementarity of the different cultural perspectives. This may sound naïve or even triumphalist, but we understand this in line with the (ongoing) conversion approach to culture which we elaborated on in Chapter 6. This implies that this is a process in which the enslaving and idolatrous function of the existing understandings is uncovered, acknowledged, and dealt with, and that at the same time new understandings are explored through trial and error. Theologically we understand this as an eschatological process which includes elements of catharsis. 
Therefore, we do not pretend to make a sketch of a 'multi-culturally integrated' discourse on science and faith, but rather to participate in a communication that facilitates the mutual understanding and testing of different cultural understandings. In this communication the question of how these perspectives both facilitate and block the growth of knowledge can be answered. In a contextual approach this question would be addressed in the light of contextual criteria. However, in the framework of a catholic approach this contextual approach is enriched by the criteria from one or more other contexts and contributes to the intercultural dialogue. The shared catholic network offers a context for constructive and critical feedback that takes cultural differences seriously and is directed towards the further development of the intercultural discourse. In this way we understand the discourse of science and religion as an intercultural space for the Spirit, as we argued in Chapter 2 (Jansen 2011).

\subsection{On the Proper Role of the North Atlantic}

However, this catholic approach as such cannot ensure the equal presentation of each of the cultural perspectives. In the introduction of this chapter we already noted that the Western bias of the debate on science and religion will not automatically disappear in a catholic approach. Our study also bears some characteristics of this as it is financed by, and academically embedded in, the North Atlantic world and takes the Western debate as its point of departure. These North Atlantic characteristics are also present in the execution of our research through the prominence of the Dutch facilitator and model builder, and in our theoretical framework which is mainly supported by Western authors. However, this North Atlantic dominance is felt considerably more strongly in the field of science than in the field of Christian faith. The participants strongly identified with Christian faith and yet no one argued that Christian faith is in fact as Western as science. The model built by the academics of Kinshasa even identified a Christian approach with the African understanding (see Chapter 5). Secularization in Western Europe and the growth of churches in the Southern hemisphere contributed to the general idea that Africa probably has a stronger position in the field of religion. However, the major part of the production of formal (academic) theology still takes place in the USA and Europe. This is representative for the whole field of scientific production in all academic disciplines.

In order to better understand the impact of the character of the West's cultural dominance in the field of science, we turn to Sandra Harding's (1998, $5^{6-61)}$ qualification of what she calls "European modern science," referring 
more specifically to natural sciences and technology but certainly not only to these. From a postcolonial perspective, she highlights four characteristics. In the first place she points to the importance of Judeo-Christian traditions that had a powerful, positive effect on the growth of modern science in Europe, "though it is common to assume that modern science can only conflict with religion" (58). This Western framing of modern science as separated from, or even opposed to, religion is one of the major themes of the discourses we reconstructed and hides its deeply Christian background. Secondly, European expansion and the development of modern science mutually influenced each other. Modern sciences therefore solve the problems identified by "an expansionist North" (58). This expansionist view creates the "distinctive patterns of knowledge and ignorance characteristic of modern sciences" (59). Thirdly, the benefits of modern science follow the same pattern and are "disproportionately distributed to the elites in the North and their allies in the South and the costs disproportionately to everyone else" (6o). Especially in the last session we had with the groups from Abidjan and Yaoundé these two latter points were explicitly discussed by the participants. Finally, according to Harding, European modern science claims to value cultural neutrality and perceives itself as culturally neutral. "Trying to maximize cultural neutrality ... expresses a culturally specific value" (61).

We provide just two remarks on Harding's first point because of its direct relation to our main subject. The Christian roots of (experimental) science and today's academic world, brings forth the question of whether there is an intrinsic bond between this kind of science and Christian faith. Harrison recalls Arthur Peacocke's claim that "the relation of Christianity to science "has a special significance for all forms of religious experience and cultures"' (Harrison 2010, 36). Harrison agrees that Christian religion is indeed a 'paradigm case' but in the sense that it is "the paradigmatic religion because the 'other religions' were constructed in its image." We agree with Peacocke's understanding of the specific relationship between Christian faith and experimental science, but we would argue differently here than Harrison. The catholic approach to intercultural theology that we advocate is directly related to the basic Christian understanding of faith and science. The basic trust in sensorial knowledge and the reliability of creation, specifically developed in Christian theology have a particular uniting meaning for the different cultural understandings of science and faith and even science and religion. One could however imagine cultural and religious contexts in which this conception is less evident or even rejected. We are aware that conditioning the dialogue on science and faith or religion by a kind of realism can easily be understood as a typically Western characteristic, 
but we think that this condition is inevitable in relation to the meaningfulness of both science (especially experimental research) and religion.

Harding's first point also refers to a complication of the North Atlantic understanding of science when it comes to its Christian roots. From being part of a symbiotic whole dominated by Christian theology and values, the dominant understanding of science in Western cultures became independent of religion, or, as Harding calls it, 'neutral'. In Chapter 5 we argued that scientism may be understood as a next step in this development. There we agreed with Smedes' cultural understanding of the term and suggested that when there is no overarching religion or philosophy, science as such can take the place of religious or philosophical worldviews. When scientific knowledge is perceived as the highest form of knowledge, science easily receives a (semi-) religious status and becomes a social and political power. Where or when this is the case in the North Atlantic world, science is no longer one of the many cultural domains but is rather the pivotal instance of culture. This indicates a new phase in the understanding of science and religion, because in such a case the typical modern separation of facts and knowledge on one side, and values and meanings on the other - as maintained by Drees $(2010,2)$ - is outdated. In such a context, scientific knowledge also provides the values. However, scientism only functions properly if science pretends to be value-, or better, culturally-neutral. This points to a contradiction within what is called cultural scientism. Anyway, the (nearly) absolute position of science in scientism makes an intercultural approach such as the one we propose very difficult. An ongoing development in the direction of scientism will therefore intensify the identification between science and the North Atlantic world, and will thus disqualify science from other cultures when it is not in line with the Western norm.

All four characteristics of Western science mentioned by Harding make it difficult to move towards a global approach in which different cultural approaches are welcomed, as we propose. Above, we suggested that the context of expansion, together with the neutrality claim (and thus directly related to what we called 'universality') of Western science, make it very difficult for the student group from Yaoundé to imagine their proper contribution to the global debate. The development towards scientism in the North Atlantic world is also a complicating factor for a global debate on science and religion.

The effect of these characteristics cannot be easily overcome. The studied discourses show that the participants from francophone Africa have (more or less) accepted the Western hegemony of science. This is not a helpful starting point for a reflection on their own cultural contribution to the global debate. In this book we challenge culturally different approaches to science and 
religion to speak out and make contributions. We deliberately choose to start the elaboration of the catholic approach on a modest scale in order to avoid the domination of Western influence. As we explained in the first part of this section, we prefer to focus on the mutual contributions that can be made by the discourses of participants in the research and Christian approaches from the North Atlantic. This places the two culturally embedded approaches in a constructive starting position. In the next section we will give an example of how this could be done, based on the results of this research. This example is to be understood as an extrapolation and a further elaboration of the first step of our catholic approach. However, we do not pretend to speak for the participants of this research (let alone for Christian academics and students from francophone Africa as whole), nor to articulate the North Atlantic position. All participants should speak for themselves and are invited to do so.

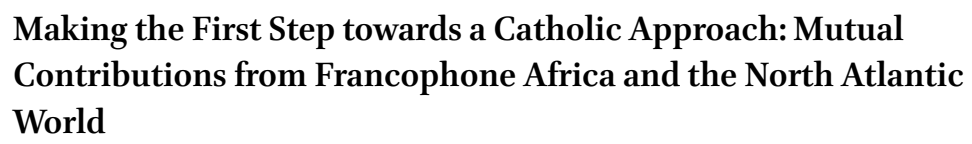

The aim of a catholic approach to science and religion is to establish an intercultural dialogue in which questions such as how the different perspectives both facilitate and block the growth of knowledge, and what each approach contributes to the other(s), can be answered. In this section we indicate venues for such a dialogue between the perspectives from francophone Africa as reconstructed by our research and understandings from the North Atlantic world.

We first answer these questions on the growth of knowledge and the contributions from the perspective from French-speaking Africa and subsequently from the perspective of the North Atlantic debate. In Chapter 2 we already pointed to the inequality of the sources. The first can be qualified as espoused theology, while for the second we use academic contributions and can therefore be qualified as formal theology. However, in the given situation, we think that a dialogue between these two different types of theology is justified and possibly fruitful.

\subsection{Contributions from the Discourses on Science and Religion from Francophone Africa}

First, we portray how the facilitating and blocking of knowledge is understood by the participants of our research, and from there we move to the question of what contributions could be made to the North Atlantic approaches. 
From the perspective of the studied discourses, Western scientific knowledge is mostly perceived as limited. There is a strong tendency among the participants to uncover a knowledge blocking element in Western science. One of the clearest understandings of this lack in Western science can be found in the discourse of the academics from Abidjan (see Chapter 5). What Western science is not able to perceive is called the spiritual, a dimension of reality which can be touched by diviners (mediums). They argue that African cultures are inclined to grasp this dimension of life. The academics themselves testified that they are aware of this dimension and use it in education when they relate to students. This element is also reflected in their understanding of research in which they refer to the guidance of the Holy Spirit and the use of prayer. In Kinshasa the academics related Western science to instrumental reasoning which is contrasted to encompassing reason. This also implies a kind of reduction on the side of Western science, more specifically located in the reasoning. Finally, we mention the two groups from Yaounde that refer to the possible negative influence of science on Christian faith. Other limiting elements of Western science mentioned can be related to its embeddedness in postcolonial politics of expansion and universality claims, both in line with Sandra Harding's analysis. According to the dominant view of the studied discourse, the Western scientific approach is thus limited qua scope and approach.

Western science normally understands itself as a specific form of knowledge acquisition, and the implication that it excludes certain domains of knowledge is quite acceptable from this self-understanding. The rules of transparency and falsification of knowledge will exclude some other types of knowledge that are none the less acceptable in other domains of life (cf. De Rijk 2010). This makes it clear that this understanding is based on an understanding of the world which is divided into (relatively) autonomous spheres. The development of the idea of separated domains of life from Aquinas' understanding of nature and grace (or post-Aquinas, according to Henri de Lubac, see Walgrave 1966; Figura 1979; Veldhuis 1990, 21-41; Dekker 2004; Bom 2009) to the Enlightenment's separation of science and truth on one side and religion and values on the other, and the nineteenth century definitions of science and religion deeply impacts Western thought. Even alternative perspectives on science, such as Sandra Harding's (1998) defence of 'strong objectivity' that includes marginal perspectives and is open to a multi-cultural dialogue on knowledge, do not mention the spiritual as an essential dimension. This 'notspiritual' approach contrasts with the encompassing approach to knowledge and reality demonstrated by the participants in the research.

The dominant perspective of the discourses present (human) life as a unity. From that perspective, the opposition of science and religion asks for a difficult, 
if not impossible, move because it requires an understanding of these realities as (relatively) independent phenomena. Although the participants can handle Western concepts, it is clear that this understanding does not fit traditional African perspectives. This corresponds to Feierman and Janzen's conclusion when it comes to science and religion in sub-Saharan Africa: "The African scholarly universe appears to be open to acceptance of religion and science in the same framework, all the while many African scientists adhere to the Western separation of science from religion" $(2011,248)$. Thus, the participants of the research do not really appropriate the Western perspective. As we commented in Chapters 4 and 6 , some of the participants understood themselves as 'hybrids' but most of them felt explicitly attached to the unity of life. They prefer living in two cultures at the same time above the separation of life. For instance, rather than being a non-religious scientist in the laboratory and a devout Christian at home and at church, some of the academics shared how they pray in the laboratory (academics from Abidjan) and how they understand their academic work as a place where God is revealed (academics from Yaoundé). Although they did not come up with typically Christian methodological or theoretical alternatives, in theirspiritual practices they unite Christian faith and science in line with the heritage of the unity of life.

All theology that in one way or another rejects the typically modern separations that are so dominant in Western culture - for example, public and private, truths and values, etc., - and perceives itself as fully scientific is at odds with the classical modern separation between science and religion. The science and religion debate is therefore at the heart of theological selfunderstanding. When African scientists stick to the unity of life, they are communicating a holistic approach. The studied discourses therefore seem to encourage the science and religion debate in the North Atlantic world to move towards a more integrated understanding of science and religion. Such an understanding is also helpful for the sake of theology itself and its place at the (post)modern university (cf. Bom et al. 2016; Bom 2016). However, in Chapter 5 we also argued that from a Western perspective integration includes the acceptance of the (relative) independence of science and religion and is therefore different from the traditional African perspective as worded by the participants. We will return to this point below.

\subsection{Contributions from North Atlantic Perspectives}

From a North Atlantic perspective, the blocking of knowledge in traditional African culture is a fact. We recall the criticism mentioned by Feierman and Janzen $(2011,245)$ about the lack of transparency of secret knowledge, and 
which was also mentioned by the students from Abidjan (see Chapter 5 ; Bom \& Toren 2017). As we mentioned before, the idea of the power of secret knowledge appeared to be strong among the research population, and various participants in the research groups alleged that Rosicrucians and Freemasons are influential at the university. In Chapter 6 we suggested that from an African perspective these esoteric societies resemble variations of traditional secret societies. Apparently, the transparency argument is not generally shared at these universities.

The relation between religious power and science therefore questions the holistic approach favoured by the participants in our research. A holistic approach easily leads to the domination of religious and other power interests over knowledge. The second session with the students from Abidjan revealed that sometimes the churches, but more often traditional forces, reject academic knowledge because it questions their knowledge and thus their power. The student group from Abidjan suggested that from the perspective of traditional leaders the strict separation of science and religion appears to be the best solution. However, this opposes the main tendency of the research which holds that science and religion are intimately related. The North Atlantic criticism points to a vulnerable side of the so-called holistic position. If the role of religion, in this case Christian faith, is not clarified, all kind of leadership can easily block knowledge.

It therefore appears to be a typical mistake from the perspective of the (European) Enlightenment to think that this threat is especially concentrated in religious leaders or even in religion as such. Blocking knowledge in SubSaharan Africa is in the first place an effect of cultural politics from the colonial powers and the post-colonial state that uses education and university for their own goals. Harding (1998) confirms this more generally for the postcolonial situation. All kinds of power are therefore a possible threat to the open acquisition of knowledge and science and can lead to abuse. Nevertheless, power is always involved, and a neutral science is impossible. We think that a critical assessment by Western approaches can make an important contribution to the worldwide debate and therefore also to the holistic approach we found in the studied discourses. The critical assessment should not however be limited to blocking but should also include the facilitation of knowledge. The science and religion debate could be helpful for clarifying all kind of links between powers, values, and knowledge in order to understand the blocking and facilitation of knowledge. It will then become evident that in Western science, governmental programs and financing by industries, etc., can easily develop into knowledge blocking elements. 
Finally, we turn to Barbour's typology, to which we referred earlier. In Chapter 5 we concluded that this typology should be expanded in order to make an intercultural debate possible. This presupposes that Barbour's typology can be a useful instrument for a catholic approach to the science and religion interface. Although we addressed some of its typical cultural limitations, we still think it can be an important tool for a catholic approach. This is especially the case because many Western understandings of science and religion are spread by colonialism, mission, and international scientific networks. However, in a non-Western cultural context the Western types or models will be interpreted differently. For example, in the conflict model the clash between science and faith, referred to by the participants and mainly related to some of the churches and the traditional leadership, is primarily a cultural conflict. The opposition of science and faith can only be understood well from the context of its defender(s). Above we argued that the context, including religion, power relations, etc., also influences Western understandings. Presenting a conflict as 'purely theoretical', without social and religious embedding is, at least from the perspective of most participants, something typically 'Western'. Including contextual elements such as culture, religion, and social situations in Barbour's typology would make it more complete and more accurate. Indicating from which cultural, social, and religious engagements a certain position in the science and religion interface is defended offers more insight into the content of this position. Smedes takes a first step in this direction by including an analysis of the North American and European scientific and specifically theological context (2008).

Nevertheless, Barbour's typology should be expanded with new 'models' as well. In Chapter 5 we highlighted the fact that the most dominant position in the researched discourses is the one that understands science and faith as being part of a bigger whole. Historically and culturally, this appears to be a broadly accepted position, as we argued above (see for example, the references to Harrison 2010 and Bagir 2015). This holistic understanding of science and faith should be recognized as a model as well. Importantly, though, this possible new model is probably more diverse than we realise from our perspective. Due to the dominance of the modern Western understanding, the positions that we characterise as a holistic perspective seem to represent one new model. However, it is likely that there is a similar diversity of positions among those who defend this holistic perspective as there is among those who separate the two. This diversity should be brought to the fore by further analysis of those positions and should be added as alternative models to Barbour's typology. 


\subsection{An Ongoing Dialogue}

It is interesting that when we start to envisage the possibilities of mutual contributions, the North Atlantic approaches and those from the studied discourses cannot be isolated. Both perspectives are challenged to open up and to broaden their perspectives. Recently, some of the approaches from Christian theology in the North Atlantic world that move in the direction of integrating science and Christian faith, are informed by the worldwide Pentecostal movement. Because of the special interest in the role of the Holy Spirit as mentioned by the academics from Abidjan as well as in our own approach (see Chapters 2 and 6), we point to two approximations from the West that combine a non-excluding perspective with a particular focus on pneumatology. In the first place we mention John Pokinghorne's approach, as presented in the article 'The Hidden Spirit and the Cosmos' (2006). Here, Polkinghorne focuses on the relation between the Spirit and 'chaos-theory'.

The author starts from a Trinitarian perspective and seeks to relate the understanding of the role of the Spirit to the discovery of the intrinsic unpredictability of nature in the natural sciences, and the interaction between 'chance' and 'necessity' (lawful regularity). The author argues that the openness to the ongoing activity presumes that God is in both. There is no doubt that natural science and theology are neatly distinguished here, but the search is characterized by the compatibility and even complementarity of the two. Another example of such an approach is the volume edited by James Smith and Amos Yong, Science and the Spirit: A Pentecostal Engagement with the Sciences (2010). Smith argues against naturalism and also advocates a double understanding of the commitment of the Spirit: "the Spirit's faithfulness and the Spirit's surprises" (43-47), which is in line with Polkinghorne's contribution. Yong includes the importance of speaking in tongues as a hermeneutical key for understanding the variety of scientific voices that "declare the glory of God." Especially in Yong's contribution, theology receives an important role in the unified understanding of what so many, and such diverse, scientists are finding. Yong is especially keen on the way divine action can be worded in relation to science in general and underlines the hermeneutical character of all sciences, including theology. This overlaps nicely with what Clément, the chemist from Abidjan, argued (see Chapter 5).

Without arguing about the specific content or proposals of these examples, these contributions are particularly important for us because these authors communicate how scientific understandings are related to God's presence and action in such a way that a fruitful dialogue with the holistic approach of the research population seems to be attainable. In the context of Polkinghorn's, 
Smith's, and Yong's texts, "Science as a place of revelation" as argued by the academics from Yaoundé makes sense.

\section{To Conclude}

In Chapter 6 we argued that in our understanding of intercultural theology we focus on the conversion of culture by Christian faith and therefore transformations of culture are important indicators. We then referred to the example of the baruti and their role in the transformation of the healthcare in Botswana (Feierman and Janzen 2011). A catholic approach to science and religion therefore mainly concentrates on the understanding and facilitation of this transformation through the knowledge of creation and God.

The studied discourses show that these African cases offer interesting ways of further understanding this transformation because there is a strong awareness of being between different cultural forces. This awareness by the participants, most explicitly by the students from Yaoundé but also palpably in the other groups, makes both a transformation of the traditional and a revision of the North Atlantic understandings probable. The overview of the major positions of the debate in the North Atlantic world by Barbour shows that there is also a discontent with the nineteenth century concepts in the Northern hemisphere. However, our review of Van Huyssteen's Alone in the World? shows how difficult it is to move beyond this discontent without the context of an intercultural encounter. Concerning the debate on science and religion, cultural transformation is therefore far more probable in Africa and in other contexts that try to deal with the hegemonic position of North Atlantic science from a different cultural context. Here our intercultural theological preference for what we called marginalized contexts (see Chapter 6) proves its relevance.

However, as in every process of conversion, the outcome is not certain. During the last research session, the students from Yaoundé expressed their doubts about whether it would really be possible to develop a proper, Cameroonian or francophone African perspective on science and Christian faith, given the economic, political, and academic power of the West. The example of Feierman and Janzen illustrates that the changes often need 'middle steps' and 'middle figures' such as the baruti. Finally, intercultural theology not only studies transformative processes of intercultural encounters but also helps to share the benefits of these changes worldwide. The effects of this are similarly uncertain, although the overcoming of the opposition between science and religion 
seems an attractive perspective for many scientists in the West (Howard Ecklund 2010). However, we have hope that when the Catholic awareness among scientists grows, that which is brought forward in one part of the worldwide community will also be fruitful in the other parts. 